\title{
Evaluation of the Abdominal Wall Vasculature in Post Bariatric Abdominoplasty: Anatomical and Pathological Study
}

\author{
TAREK ZAHRA, M.D.*; AHMED M. ZEINA, M.D.*; ABDELHADI MOHAMED SHEBL, M.D.**; \\ AMR MOHAMED KHATER, M.D.*; MOHAMMED RADWAN ELHADIDY, M.D.* and \\ MOSTAFA ABD HALIM, M.D.* \\ The Departments of Plastic \& Reconstructive Surgery* and Pathology**, Faculty of Medicine, Mansoura University
}

\begin{abstract}
Following bariatric surgery, the body contouring had a crucial role in achieving a satisfactory result for the patients. Hematoma and bleeding are higher in post bariatric patients probably due to prolonged protein and vitamins deficiencies and deficient clotting factors. The study subjects were divided equally into three groups, each group contains 5 patients, where; group A: Included patients with BMI 25-30 with history of bariatric surgery in the past two years after at least six months of stable weight, group B: Included patients with BMI 25-30 with no history of weight loss or bariatric surgery and group C: Included patients with BMI more than 30 with no history of weight loss or bariatric surgery. Tissue specimen from the lower abdomen including superficial epigastric artery and vein with fat sent for pathological examination. The mean superficial inferior epigastric artery diameter was $1.7 \mathrm{~mm}$ in group A, $1.4 \mathrm{~mm}$ in group B and $1.6 \mathrm{~mm}$ in group $\mathrm{C}$. The mean thickness of inferior epigastric artery thickness was $92.242 \mathrm{um}$ in group A, 104.032um in group B and a mean of 106.038um in group C. WE have two measurements the diameter and the wall thickness. The mean superficial inferior epigastric vein diameter was $2.9 \mathrm{~mm}$ in group A, $2 \mathrm{~mm}$ in group B and $2.9 \mathrm{~mm}$ in group $\mathrm{C}$. The mean thickness of inferior epigastric vein thickness was $34.442 \mathrm{um}$ in group A, 42.94um in group B and a mean of $67.99 \mathrm{um}$ in group C. In postbaiatric patients it was noticed intraoperatively that the blood vessels were dilated, friable so it need more meticulous hemostasis.
\end{abstract}

Key Words: Abdominoplasty - Bariatric surgery - Obesity Superficial epigastric.

\section{INTRODUCTION}

According to the World Health Organization (WHO), obesity is described as a BMI $\geq 30$ [6]. to reduce the morbidity associated with obesity, the current guidelines suggest a weight loss of at least $5 \%$ body weight in patients with a BMI $\leq 35$ and a weight loss of at least $10 \%$ body weight in patients with a BMI $\leq 35$ [1].

Metabolic syndrome and its inflammatory and atherogenic sequelae are closely associated with obesity. In the treatment of endothelial dysfunction and atherosclerosis, various adipocytokines were also suggested [2,3]. Furthermore, obesity can lead to difficulties in everyday life, hamper the quality of life and generate psychological disorders as a devalued self-image and depression [4].

Atherosclerosis is one of the main causes of morbidity and mortality all over the world, and the pandemics of obesity and type 2 diabetes (T2DM) are the main contributors to worsening this scenario in the next decades. Fighting atherosclerosis involves controlling of obesity and T2DM $[5,6]$.

Bariatric surgery is the treatment of choice in advanced cases to help weight loss with limited complications [7]. According to the 2018 German Guideline for Adiposity and Metabolic Disease Surgery, surgical therapy is recommended in patients with a BMI of 40 , in patients with a BMI of 35 to 40 and in patients with a BMI of 30 to 35 and type 2 diabetes mellitus [8].

Bariatric surgery is of tremendous effect in managing obesity and T2DM. Besides, it lessens the incidence of cardiovascular events [9], improves the inflammatory processes and metabolic pathway in addition to losing weight. Also, bariatric surgery improves the arteriovenous ratio of the peripheral vessels [10].

The fast increase in obesity has been followed by the growth in the demand for plastic surgery in those obese patients. Weight loss may lead to some sort of disorders and dysfunctions of the body contour which may negatively impact the quality of life [11].

However, about $89 \%$ of the patients after bariatric surgeries complain of complications, particularly redundant skin and up to half of these patients 
find this condition is worse than obesity itself. Therefore, following bariatric surgery, the body contouring plays a crucial role in achieving a satisfactory result for the obese patients [12].

Therefore, the patients who underwent postbariatric surgery primarily ask for body contouring, to remove the excess skin, hanging loose after this dramatic weight loss. Therefore, abdominoplasty is a plastic surgery of great demand to remove that excess skin and redundant fat for proper body shaping [13].

During abdominoplasty following the bariatric surgery, where large areas of highly vascularized subcutaneous tissues and skin are excised, this can result in considerable blood loss. According to Fraccalvieri et al., anemia is the $2^{\text {nd }}$ most common complication of post bariatric abdominoplasty [14].

Abdominoplasty may lead to serious complications. In evidence-based studies, the overall early complication rate ranges from $45 \%$ to $70 \%$. Several factors appear to be involved in the development of these complications of the wound, including preoperative factors, intraoperative factors and surgical factors [15].

Complication of post bariatric abdominoplasty include seroma, wound-healing problems, hematoma, infection, skin flap necrosis, wound dehiscence, deep vein thrombosis and pulmonary embolism, whereas wound healing disorders and seroma formation appear to be by far the most common [12].

Hematoma and bleeding are higher in post bariatric patients probably due to prolonged protein and vitamins deficiencies and deficient clotting factors [16].

In our practice of post bariatric abdominoplasty, we noticed that blood vessels are considerably larger, more friable and need meticulous control of their bleeding. Therefore, we carried this study to assess the effect of bariatric surgery on blood vessels.

\section{Objectives:}

To study the effect of bariatric surgery on vessels of anterior abdominal wall in comparison to normal population.

\section{PATIENTS AND METHODS}

This is a prospective study involving 15 patients seeking abdominoplasty who were recruited from the outpatient clinic of Mansoura Burn and Plastic Surgery Center and was conducted over a period of eight months starting from November 2018 till June 2019. The study was approved by the Institu- tional Review Board (IRB) of the Mansoura Faculty of Medicine (R.18.10.312).

The study subjects were divided equally into three groups, each group contains 5 patients, where; group A: Included patients with BMI 25-30 with history of bariatric surgery in the past two years after at least six months of stable weight, group B: Included patients with BMI 25-30 with no history of weight loss or bariatric surgery and group C: Included patients with BMI more than 30 with no history of weight loss or bariatric surgery.

Patients with poor health including advanced cardiopulmonary disease, liver cirrhosis, hypertension, or coagulopathies, smokers and uncontrolled diabetes are excluded. Data concerning age, gender, weight loss, and the superficial inferior epigastric vessels (diameter and thickness) were collected and compared among the three groups.

\section{Preoperatively:}

Prior to surgery, the patients were subjected to the following:

- Evaluated by the pulmonary and cardiologist to optimize lung and heart function.

- Seen by the anesthesiologist to ensure that the patient is fit for general anesthesia.

- Abdominoplasty need no special equipment.

\section{Preparation:}

A patient's medical health should be wellprepared before surgery. Appropriate clearances should be obtained; any underlying illnesses that would preclude the patient from the procedure should be prematurely excluded. Appropriate antibiotics should be given in the preoperative period to lessen the incidence of the contamination of the wound by skin flora.

\section{Technique:}

The patient is anaesthetized and placed in supine position. The patient is prepared from breast to knees with povidone iodine. The incision is made from ASIS to ASIS through the natural suprapubic crease and extends laterally depending on extent of redundancy. It is performed low enough to obscure any scar in the bikini line $7-8 \mathrm{~cm}$ above the vulval commissure. (Fig. 1).

Assessment of Superficial epigastric artery and vein were done intraoperatively at the lower abdominal incision, the vessels were traced for 3$4 \mathrm{~cm}$ (Fig. 2), and its size was recorded using a ruler (Fig. 3). A piece of the subcutaneous tissue including vessels and fatty tissue was excised and 
preserved in formalin and sent for pathological examination (Fig. 4). Completion of abdominoplasty procedure was completed with excess skin excision, liposuction plication of the rectus sheath, umbilical stalk repositioning and multiple layer closure with drains in place.

Specimens are fixed and set in paraffin in 10 percent of the neutral buffered formalin solution. Four-micrometer sections were stained with hematoxylin and eosin (H\&E). The slides were examined for histopathological changes by a pathologist using light microscopy. The measurements were assessed using camera.

\section{Postoperative care:}

Postoperatively, the patient was kept in a flexed (Semi-Fowler) position for 2 weeks. A belt lipec-

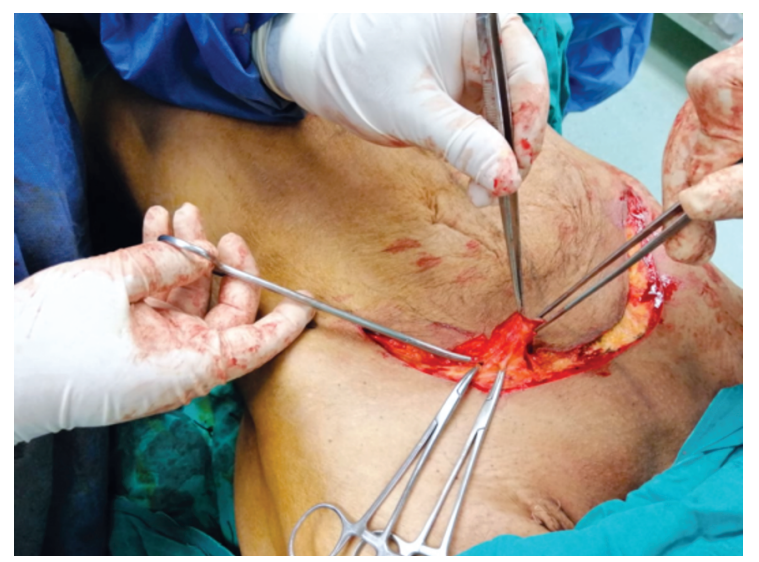

Fig. (1): Extent of the incision.

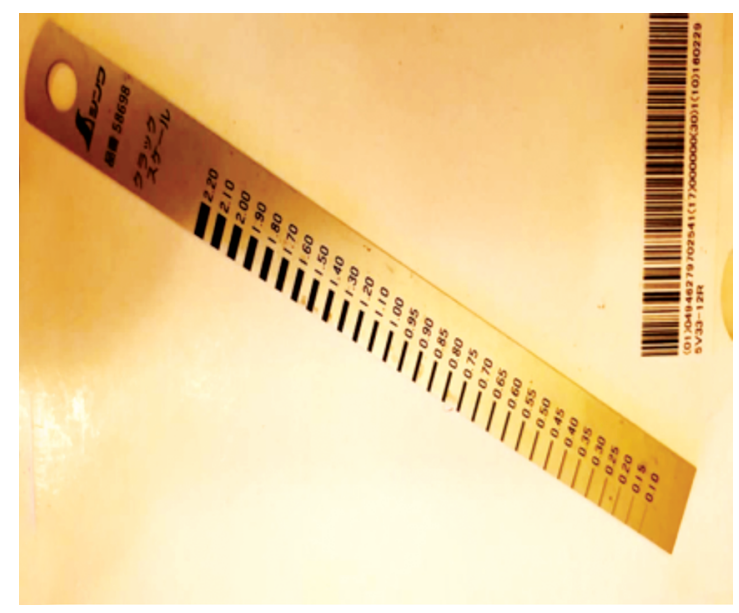

Fig. (3): Ruler used for measurement of the vessels diameter.

\section{RESULTS}

We had one third of our study sample were males $(33.33 \%)$, the mean age of our study sample was 36 years. (Table 1 ). tomy was considered in patients with significant flank, buttock, and thigh fat, to help thigh and buttocks lift with the abdominoplasty. Closed suction drains and oral antibiotics were used to prevent infection and other complications such as seroma, surgical wound infection and hematoma formation. consultations were made one week after discharge with referrals if needed. Drains were removed after 4-5 days. Early ambulation was ensured to limit deep vein thrombosis.

\section{Statistical analysis:}

The data were analyzed using Statistical Package of Social Science (SPSS). The results were presented in the form of number and percentages. Significance was considered at $p<0.05$.

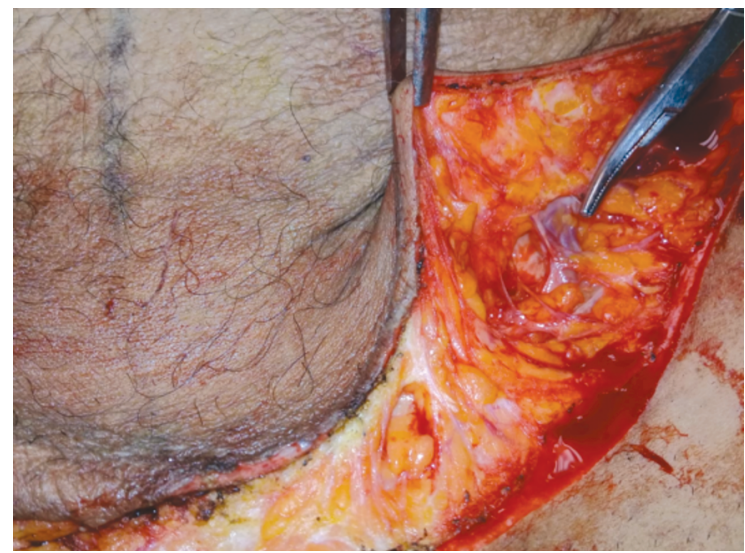

Fig. (2): Tracing of superficial iliac artery and vein.

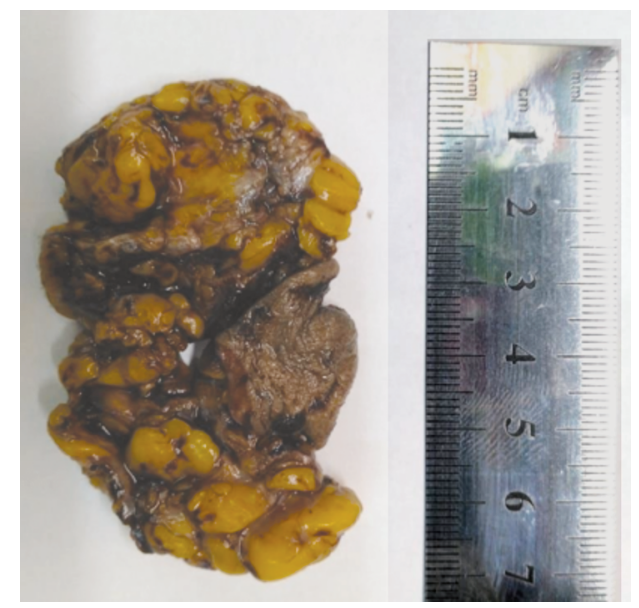

Fig. (4): Specimen of fatty tissue containing superficial epigastric artery and vein.

As regards the complication, two patients (40\%) from group A suffered from delayed wound healing that was managed with frequent dressing, whereas, two patients had seroma one from group $\mathrm{A}$ and the 
other from group C (Table 2). Our results showed Post-bariatric patients have a higher rate of complication following abdominoplasty compared to non-bariatric patients.

The mean diameter of superficial inferior epigastric artery was $1.7 \mathrm{~mm}$ in group A, $1.4 \mathrm{~mm}$ in group B and $1.6 \mathrm{~mm}$ in group $\mathrm{C}$. The mean thickness of inferior epigastric artery thickness was 92.242um in group A, 104.032um in group B and a mean of 106.038um in group C. Two measurements the diameter and the wall thickness explained in (Tables 3,4).

The mean superficial inferior epigastric vein diameter was $2.9 \mathrm{~mm}$ in group A, $2.4 \mathrm{~mm}$ in group $\mathrm{B}$ and $2.9 \mathrm{~mm}$ in group $\mathrm{C}$. The mean thickness of inferior epigastric vein thickness was $34.442 \mathrm{um}$ in group A, 42.94um in group B and a mean of 67.99um in group C. (Tables 5,6), (Figs. 5,7).

Table (1): The Demographic characters of the participants.

\begin{tabular}{|c|c|c|c|c|c|c|}
\hline \multirow{2}{*}{ Variables } & \multicolumn{2}{|c|}{ Group A $(n=5)$} & \multicolumn{2}{|c|}{ Group B $(n=5)$} & \multicolumn{2}{|c|}{ Group C $(n=5)$} \\
\hline & Number & Percentage & Number & Percentage & Number & Percentage \\
\hline \multicolumn{7}{|l|}{ Gender: } \\
\hline Male & 3 & 60.0 & 2 & 40.0 & 0 & 0.0 \\
\hline Female & 2 & 40.0 & 3 & 60.0 & 5 & 100.0 \\
\hline \multicolumn{7}{|l|}{ Age (20-45): } \\
\hline $25-30$ & 2 & 40.0 & 3 & 60.0 & 1 & 20.00 \\
\hline $35-40$ & 1 & 20.00 & 0 & 0.0 & 2 & 40.00 \\
\hline$>40$ & 2 & 40.0 & 2 & 60.0 & 2 & 40.00 \\
\hline
\end{tabular}

Table (2): Complications after abdominoplasty.

\begin{tabular}{lccccccccc}
\hline \multirow{2}{*}{ Variables } & \multicolumn{2}{c}{ Group A $(\mathrm{n}=5)$} & & \multicolumn{2}{c}{ Group B $(\mathrm{n}=5)$} & & \multicolumn{2}{c}{ Group C $(\mathrm{n}=5)$} \\
\cline { 2 - 3 } & Number & Percentage & & Number & Percentage & & Number & Percentage \\
\hline Delayed wound healing & 2 & 40.0 & & 0 & 20.0 & & 0 & 0.0 \\
Seroma & 1 & 20.0 & & 0 & 0.0 & & 1 & 0.0 \\
Umbilical necrosis & 0 & 0.0 & & 0 & 0.0 & & 0 & 0.0 \\
Postoperative bleeding & 0 & 0.0 & & 0 & 0.0 & & 0 & 0.0 \\
\hline
\end{tabular}

Table (3): Diameter of superficial inferior epigastric artery.

\begin{tabular}{lcccccccc}
\hline \multicolumn{7}{c}{ Diameter (artery) mm } \\
\hline Gr A & Number & Percentage & Gr B & Number & Percentage & Gr C & Number & Percentage \\
\hline$<1.7 \mathrm{~mm}$ & 1 & 20.0 & $<1.4 \mathrm{~mm}$ & 2 & 40.0 & $<1.6 \mathrm{~mm}$ & 1 & 20.0 \\
$1.7 \mathrm{~mm}$ & 3 & 60.0 & $1.4 \mathrm{~mm}$ & 2 & 40.0 & $1.6 \mathrm{~mm}$ & 3 & 60.0 \\
$>1.7 \mathrm{~mm}$ & 1 & 20.0 & $>1.4 \mathrm{~mm}$ & 1 & 20.0 & $>1.6 \mathrm{~mm}$ & 1 & 20.0 \\
\hline Gr: Group.
\end{tabular}

Table (4): Thickness of superficial inferior epigastric artery.

\begin{tabular}{lccccccc}
\hline \multicolumn{7}{c}{ Thickness um (artery) } \\
\hline Gr A & Number & Percentage & Gr B & Number & Gr C & Number & Percentage \\
\hline$<92.242$ & 3 & 60.0 & $<104.032$ & 3 & $<106.038$ & 2 & 40.0 \\
$>92.242$ & 2 & 40.0 & $>104.032$ & 2 & $>106.038$ & 3 & 60.0 \\
\hline
\end{tabular}

Table (5): Diameter of superficial inferior epigastric vein.

\begin{tabular}{lcccccccc}
\hline \multicolumn{7}{c}{ Diameter (vein) $\mathrm{mm}$} \\
\hline Gr A & Number & Percentage & \multicolumn{1}{c}{ Gr B } & Number & Percentage & Gr C & Number & Percentage \\
\hline$<2.9 \mathrm{~mm}$ & {[} & 40.0 & $<2.4 \mathrm{~mm}$ & 2 & 40.0 & $<2.9 \mathrm{~mm}$ & 3 & 60.0 \\
$2.9 \mathrm{~mm}$ & 2 & 40.0 & $2.4 \mathrm{~mm}$ & 2 & 40.0 & $2.9 \mathrm{~mm}$ & 2 & 40.0 \\
$>2.9 \mathrm{~mm}$ & 1 & 20.0 & $>2.4 \mathrm{~mm}$ & 1 & 20.0 & $>2.9 \mathrm{~mm}$ & 0 & 96.0 .0 \\
\hline
\end{tabular}


Table (6): Thickness of superficial inferior epigastric vein.

\begin{tabular}{lccccccc}
\hline \multicolumn{7}{c}{ Thickness um (vein) } \\
\hline Gr A & Number & Percentage & Gr B & Number & Gr C & Number & Percentage \\
\hline$<34.442$ & 2 & 40.0 & $<42.94$ & 3 & $<67.99$ & 2 & 40.0 \\
$>34.442$ & 3 & 60.0 & $>42.94$ & 2 & $>67.99$ & 3 & 60.0 \\
\hline
\end{tabular}

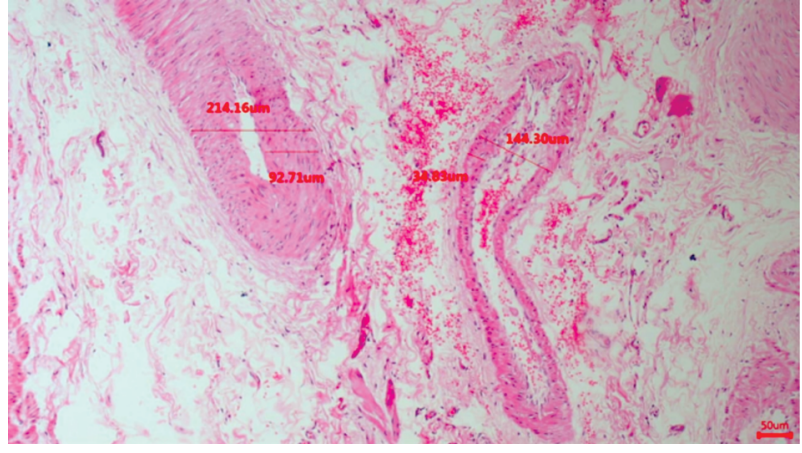

Fig. (5): Histological appearance of the superficial artery and vein in group $\mathrm{A}$.

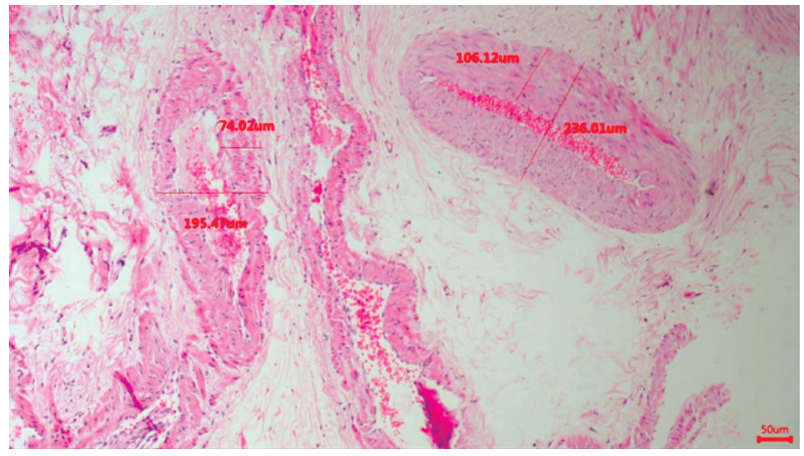

Fig. (7): Histological appearance of the superficial artery and vein in group $\mathrm{C}$.

\section{DISCUSSION}

Obesity is positively correlated with the high carotid intima-media thickness (CIMT), which is considered a prognostic factor for future cardiovascular disease (CVD), and is correlated closely to atherosclerosis [17].

An abnormally increased CIMT correlates with obesity and the high prevalence and incidence of CVD [18]. Adipose tissue also correlates with the CIMT thickening. The possible mechanisms may be attributed to some cytokines, as leptin, besides, inflammatory and immune effects. Modest weight loss achieved through diet and lifestyle interventions help the improvement of the C-IMT in obese children. Evidence-based studies show that the regional fat distribution, rather than total fat mass, plays a major role in determining the metabolic outcome. Abdominal obesity is more likely to be linked to arteriosclerosis than simple obesity [19].

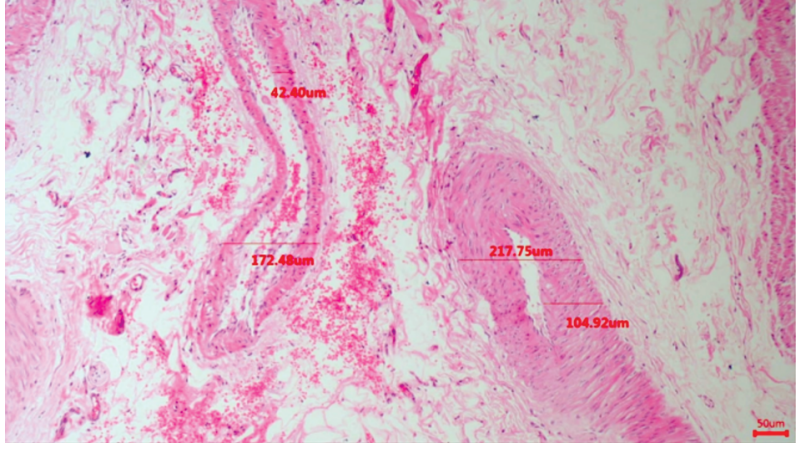

Fig. (6): Histological appearance of the superficial artery and vein in group B.

According to the literature, post-bariatric patients present with more complications in body contouring surgery compared with those patients who lost weight from dieting or physical activity $(50 \%$ vs $30 \%)$ because of the greater amount of tissue to be resected, high BMI, and nutritional factors [21].

We reported that post-bariatric patients have a higher rate of complication following abdominoplasty compared to non-bariatric patients, which was supported in other studies [22-24]. This may be attributed to the effect of nutritional deficiencies, which are common following bariatric surgery; on wound related complications in post-bariatric patients has been the subject of an increasing number of reports [23-25], which comes in line with our results. Agha-Mohammadi and Hurwitz stated that nutritional deficiencies develop after bariatric surgery, with greater micronutrient and macronutrient deficiencies for malabsorption, especially in patients with history of gastric bypass, adversely affecting wound healing due to higher nutritional requirements [26]. Other studies reported different results from ours concerning the post bariatric abdominoblasty, where seroma was the commonest complication [27].

Body contouring procedures are gaining attention nowadays, though being associated with a high complication rate. Wound healing problems are especially frequent. Nutrients important for wound healing are frequently deficient after gastric bypass surgery. One hypothesis might be that these deficiencies are (in part) responsible for the high complication rate in postbariatric body contouring 
surgery. Prospective studies focusing on the causal relationship between preoperative deficiencies and the occurrence of post-operative complications in post-bariatric body contouring surgery are lacking so far [21].

In our study we found that the effect of bariatric surgery on the blood vessels of anterior abdominal wall is very noticeable. The diameter is increased and the wall thickness is decreased, where the mean superficial inferior epigastric artery diameter was $1.7 \mathrm{~mm}$ in group A, $1.4 \mathrm{~mm}$ in group B and $1.6 \mathrm{~mm}$ in group $\mathrm{C}$. The mean thickness of inferior epigastric artery thickness was 92.242 um in group A, 104.032um in group B and a mean of 106.038 um in group $\mathrm{C}$ and the mean superficial inferior epigastric vein diameter was $2.9 \mathrm{~mm}$ in group A, $2 . \mathrm{mm}$ in group $\mathrm{B}$ and $2.9 \mathrm{~mm}$ in group $\mathrm{C}$. The mean thickness of inferior epigastric vein thickness was 34.442 um in group A, 42.94um in group B and a mean of 67.99 um in group $C$. This could be attributed to the prolonged nutritional and vitamins deficiency causing the thickness of the vessels wall to be less and more fragile.

Histopathological assessment of post-bariatric skin surgery samples showed a poorly organized collagen structure, elastin degradation, and macroscopically normal scar formation regions. The skin tissue in those subjects showed dramatic change to the extracellular matrix components in spite of the time since the bariatric procedure [28].

Obesity leads to vascular damage, loss of function of fat or perivascular adipose tissue (PVAT) surrounding arteries. PVAT covers most blood vessels in the body and includes immune cells, stem cells and microvasculature in addition to adipocytes. In normal subjects, PVAT controls the contractile tone of the adjacent small arteries by secreting vasodilatory molecules, which act independently of the endothelium and include adiponectin, hydrogen sulfide, and palmitic acid methyl ester [29].

PVAT's functional damage and recovery after bariatric surgery is fully consistent with this fat hypothesis hypoxia/inflammation. Accordingly, in previous studies, adipocyte hypertrophy and TNF staining in adipose tissue associated with loss of PVAT vasodilatory function were reported. Nevertheless, after bariatric surgery, PVAT vasodilatory capacity is restored to a degree close to that found in healthy patients who are not obese. It is interesting to note that even though the patients are still severely obese, this functional recovery of PVAT occurs. Improvement in PVAT function after sur- gery is associated with smaller adipocytes (in the sense of a dramatic weight loss), reduction of PVAT TNF and increased local adipose tissue. This is consistent with other studies that showed significant reductions in macrophage numbers as well as monocyte chemoattractant protein-1 and hypoxiainducible factor- $1 \alpha$ in the white adipose tissue stromal vascular fraction after bariatric surgery and improvement of vasodilatory function in subcutaneous fat due to restitution of PVAT-derived adiponectin [30].

There are some limitations in our study, being of small sample size, which hinders the generalization of our results. Also, this study is a single center study and multicenter studies are needed to support our findings. Also there are some confounding factors that were not assessed in our study as prior weight before weight loss either through bariatric surgery or weight loss. However, we have a number of strengths in our study, one of the main strengths in our study, is that it is considered one of the premier study to study the effect of bariatric surgery on the blood vessels of anterior abdominal wall.

\section{Conclusions:}

Abdominoplasty is an effective surgical procedure for the correction of body contouring in patients with extensive weight loss post-bariatric surgery. However, with higher risk of complications compared to abdominoplasty without prior bariatric surgery. Also, our study offers an insight into the mechanism by which bariatric surgery improves vascular function. However, it was noticed intraoperatively that the blood vessels were dilated, friable and need more meticulous hemostasis. This could be attributed to the prolonged nutritional and vitamins deficiencies causing the thickness of the vessels wall to be less and more fragile.

\section{Conflict of interest:}

The author declared no conflict of interest.

\section{REFERENCES}

1- Scaglione R., Di Chiara T., Cariello T., et al.: Visceral obesity and metabolic syndrome: Two faces of the same medal? Intern. Emerg. Med., 5: 111-119, 2010.

2- Van Gaal L.F., Mertens I.L. and De Block C.E.: Mechanisms linking obesity with cardiovascular disease. Nature, Vol. 4; (44): 875-880, 2006.

3- Rosa S.C., de Macedo J.L.S., Canedo L.R. and Casulari L.A.: Quality of life and predictive factors for complications in patients undergoing abdominoplasty after gastric bypass: A retrospective cohort. Surgery for Obesity and Related Diseases, Vol. 15, (3): 447-455, 2019. 
4- Sjöström L., Peltonen M., Jacobson P., et al.: Bariatric surgery and long-term cardiovascular events. JAMA, 307: 56-65, 2012.

5- World Health Organisation. Obesity and overweight. Available from: URL: http://www.who.int/en/newsroom/fact-sheets/detail/obesity-and-overweight. [Last accessed on 7 Aug 2018].

6- González-Muniesa P., Mártinez-González M.A., Hu F.B., Després J.P., Matsuzawa Y., Loos R.J.F., Moreno L.A., Bray G.A., Martinez J.A.: Obesity. Nat. Rev. Dis. Primers, 3: 17034, 2017.

7- Bray G.A., Frühbeck G., Ryan D.H. and Wilding J.P.H.: Management of obesity. Lancet, 387: 1947-56, 2016.

8- AWMF online. S3-Leitlinie: Chirurgie der Adipositas und metabolischer Erkrankungen. Available from: http://www.awmf.org/uploads/tx_szleitlinien/088$001 \mathrm{~m} \_S 3$ _Chirurgie-Adipositas-metabolischeErkrankugen_2018-02.pdf. Last accessed on 7 Aug., 2018.

9- Bays H.E., Laferrere B., Dixon J., et al.: Adiposopathy and bariatric surgery: Is 'sick fat' a surgical disease? Int. J. Clin. Pract., 63: 1285-1300, 2009.

10- Datta G., Cravero L., Margara A., et al.: The plastic surgeon in the treatment of obesity. Obes. Surg., 16 (1): 5-11, 2006.

11- Cintra W.Jr., Modolin M.L., Gemperli R., et al.: Quality of life after abdominoplasty in women after bariatric surgery. Obes. Surg., 18 (6): 728-32, 2008.

12- Bota O., Schreiber M., Bönke F., Teather D. and Dragu A.: Wound healing in postbariatric body contouring surgery. Plast. Aesthet. Res., 5: 30, 2018.

13- Giordano S., Kangas R., Veräjänkorva R. and Koskivuo I.: Ligasure impact ${ }^{\mathrm{TM}}$ might reduce blood loss, complications, and re-operation occurrence after abdominoplasty in massive-weight-loss patients: A Comparative Study. Scandinavian Journal of Surgery, 1-8. 2019.

14- Montano-Pedroso J.C., Garcia E.B., Omonte I.R., Rocha M.G. and Ferreira L.M.: Hematological variables and iron status in abdominoplasty after bariatric surgery. Obes. Surg., 23 (1): 7-16. 2013.

15- Kitzinger H.B., Cakl T., Wenger R., Hacker S., Aszmann O.C. and Karle B.: Prospective study on complications following a lower body lift after massive weight loss. J. Plast. Reconstr. Aesthet. Surg., 66: 231-8. 2013.

16- Wunsch R., de Sousa G., Toschke A.M., Reinehr T.: Intima-media thickness in obese children before and after weight loss. Pediatrics, 118 (6): 2334-40, 2006.

17- Jin Y., Kim D., Cho J., Lee I., Choi K., et al.: Association between Obesity and Carotid Intima-Media Thickness in Korean Office Workers: The Mediating Effect of Physical Activity. BioMed Research International, Vol. 2018; (4285038): 1-10, 2018.

18- Lamotte C., Iliescu C., Libersa C. and Gottrand F.: In- creased intima-media thickness of the carotid artery in childhood: A systematic review of observational studies. European Journal of Pediatrics, Vol. 170; (6): 719-729. 2011.

19- Wang Y., Ma X., Zhou M., et al.: Contribution of visceral fat accumulation to carotid intima-media thickness in a Chinese population. Int. J. Obes. (Lond), 36 (9): 12038. 2012.

20- Van der Beek E.S., van der Molen A.M. and van Ramshorst B.: Complications after body contouring surgery in postbariatric patients: The importance of a stable weight close to normal. Obes. Facts, 4: 61-66. 2011.

21- Staalesen T., Olsén M.F. and Elander A.: Complications of abdominoplasty after weight loss as a result of bariatric surgery or dieting/postpregnancy. J. Plast. Surg. Hand Surg., 46: 416-420, 2012.

22- Greco J.A., Castaldo E.T., Nanney L.B., et al.: The effect of weight loss surgery and body mass index on wound complications after abdominal contouring operations. Ann. Plast. Surg., 61: 235-242, 2008.

23- Agha-Mohammadi S. and Hurwitz D.J. Enhanced recovery after body-contouring surgery: Reducing surgical complication rates by optimizing nutrition. Aesthetic Plast. Surg., 34: 617-625, 2010.

24- Hasanbegovic E. and Sorensen J.A.: Complications following body contouring surgery after massive weight loss: A meta-analysis. J. Plast. Reconstr. Aesthet. Surg., 67: 295-301, 2014.

25- Naghshineh N., O'Brien Coon D., McTigue K., et al.: Nutritional assessment of bariatric surgery patients presenting for plastic surgery: A prospective analysis. Plast. Reconstr. Surg., 126: 602-610, 2010.

26- Agha-Mohammadi S. and Hurwitz D.J.: Nutritional deficiency of post-bariatric surgery body contouring patients: What every plastic surgeon should know. Plast. Reconstr. Surg., 122: 604-613, 2008.

27- Grignaffini E., Grieco M.P., Bertozzi N., Raposio E., et al.: Post-bariatric abdominoplasty: Our experience. Acta. bio-medica: Atenei Parmensis., 86 (3): 278-282, 2015.

28- Light D., Arvanitis G.M., Abramson D. and Glasberg S.B.: Effect of weight loss after bariatric surgery on skin and the extracellular matrix. Plast. Reconstr. Surg., 125 (1): 343-51, 2010.

29- Lee Y.C., Chang H.H. and Chiang C.L.: Role of perivascular adipose tissue-derived methyl palmitate in vascular tone regulation and pathogenesis of hypertension. Circulation, 124: 1160-1171, 2011.

30- Aghamohammadzadeh R., Greenstein A.S., Yadav R., et al.: Effects of bariatric surgery on human small artery function: Evidence for reduction in perivascular adipocyte inflammation, and the restoration of normal anticontractile activity despite persistent obesity. J. Am. Coll. Cardiol., 62 (2): 128-135, 2013. 